BMJ Open Sport \& Exercise Medicine

\section{A game for all shapes and sizes? Changes in anthropometric and performance measures of elite professional rugby union players 1999- 2018}

To cite: Bevan T, Chew S, Godsland I, et al. A game for all shapes and sizes? Changes in anthropometric and performance measures of elite professional rugby union players 1999-2018. BMJ Open Sport \& Exercise Medicine 2022;8:e001235. doi:10.1136/ bmjsem-2021-001235

\section{- Additional supplemental} material is published online only. To view, please visit the journal online (http://dx.doi. org/10.1136/bmjsem-2021001235).

Accepted 3 February 2022

\section{Check for updates}

(C) Author(s) (or their employer(s)) 2022. Re-use permitted under CC BY-NC. No commercial re-use. See rights and permissions. Published by BMJ.

${ }^{1}$ Cardiff Blues Rugby Club, Cardiff, UK

${ }^{2}$ Endocrinology \& Diabetes, Imperial College Healthcare NHS Trust, London, UK ${ }^{3}$ Division of Diabetes, Endocrinology \& Metabolism, Department of Medicine, Faculty of Medicine, Imperial College London, London, UK

Correspondence to Dr Neil E Hill; neil.hill@nhs.net

\section{ABSTRACT \\ Background Rugby union player size has increased} since the game turned professional in 1995. Changes in physical and performance capability over this period have yet to be fully described.

Hypothesis Increases in player momentum would result from changes in body mass.

Methods Within-player rates of change in anthropometric and kinetic variables with season played were sampled in three successively studied professional rugby union club cohorts playing at the highest level of European competition between 1999 and 2019. Data comprised 910 seasons of observation for 291 elite male players. Most players had 2, 3 or 4 seasons of observation. Mixed-effects modelling distinguished changes independent of position played, club and international status.

Results With each season played, player body mass, fat-free mass and maximum speed increased significantly, while per cent fat decreased. The mean maximal velocity of a rugby player in 1999 was $8.2( \pm 0.18) \mathrm{m} / \mathrm{s}$, which in 2019 had risen to $9.1( \pm 0.10) \mathrm{m} / \mathrm{s}$. Player's momentum in 2019 was $14 \%$ more than those playing in 1999. In the Front Five, momentum increased in this period by $>25 \%$, mainly driven by greater running speed, disproving our hypothesis.

Conclusions The momentum of players, particularly forwards, increased markedly over 20 seasons of professional rugby. The resulting forces generated in collisions are thus significantly greater, although these may be mitigated by better player conditioning. Proactive regulation to address player safety may be required to address the changing nature of anthropometric measures and physical performance, minimising injury rates and potential long-term sequelae.

\section{INTRODUCTION}

Since elite rugby union became professional in 1995, an off-the-field 'arms race' has ensued whereby professional coaches, physical conditioners and medical staff now provide elite quality training, facilities and nutrition to maximise physical performance. ${ }^{1}$ In the 25

\section{Key messages}

What is already known on this topic

- The body mass of rugby players has increased since the game became professional.

What this study adds

- Over 20 seasons of elite professional rugby union, players have gained body mass and lean mass, and increased their maximal running speed.

- Players' overall momentum has increased by $14 \%$; the Front Five players' momentum has increased by $25 \%$, driven mainly by increased running speed.

How this study might affect research, practice or policy

- Increased momentum of professional rugby players may lead to greater injury frequency and severity, raising concerns about player welfare.

years of professional play, the elite level of the game is remarkable for the physical size of players. ${ }^{23}$ Many studies have shown longitudinal anthropometric changes occurring in various playing cohorts. ${ }^{14-8}$ Questionnaire surveys of former players suggest that the average professional rugby career lasts 7-9 years. $^{9} 10$

The rules of the game of rugby have evolved during this period, including allowing competition for the ball on the ground after a tackle and increasing the number of substitutions permitted to eight. ${ }^{11}$ These rule changes have enabled teams to select larger players who can compete physically and introduce fresh players when these bigger players tire. ${ }^{12}$ This means cardiovascular endurance fitness has become less important, allowing more large muscular players within the starting squad to replace one another throughout the match. ${ }^{12}$ Some studies have hypothesised that law changes in the game have directly impacted the players' physical developments. ${ }^{2}$ How 
these physical changes develop, and in what areas, are of interest to project the development of the game and the standards which players of the future might aim for, as well as carrying significant repercussions for acute and long-term player safety. ${ }^{13-16}$ Descriptions of players' physical changes may inform re-appraisal of aspects of the game that may be associated with a risk to player welfare, as well as maintaining the game as an entertaining spectacle where skill, speed and strategy play as much of a part as size.

We aimed to assess the longitudinal changes in mass, velocity, momentum and peak kinetic energy using two decades of standardised elite and international rugby player data.

\section{METHODS}

This was an observational study with measures repeated in successive seasons for most players. Male rugby union players employed by three professional rugby union clubs were represented, with data collected over 20 years from the 1999-2000 season to the 2018-2019 season. Each team played at the highest level of European club rugby during the specified timeframe. One squad's data were collected from 1999 to 2003, the next from 2004 to 2013 and the third from 2014 to 2019. Players' anthropometric (body mass and composition) measures were recorded, and physical capability (maximal running speed) was assessed.

\section{Players}

All players were in the men's senior squad for at least one season at each club. All participants were at least 17 years old. A cohort of 291 players was analysed; 66 at club 1 (1999-2003), 143 at club 2 (2004-2013) and 82 at club 3 (2013-2019). Of these, 130 (69 forwards and 61 backs) had played international-level rugby, and 161 (94 forwards and 67 backs) remained at elite club level.

\section{MEASUREMENTS}

Body mass (Seca scales, Hamburg, Germany; accuracy 0.1 $\mathrm{kg}$ ) was measured up to five times per week at training, and the weekly mean body mass was recorded. The mean of each weekly score was used to determine a seasonal mean body mass. Body mass measurements were standardised with players measured in a fasted state in the morning, unshod, wearing shorts and a lightweight top.

Body composition was determined by skinfold thickness measured with calibrated Harpenden callipers (Body Care, Kenilworth, UK), as described in the Anthropometric Standardisation Reference Manual. ${ }^{17}$ All measurements were undertaken by personnel accredited by the International Society for the Advancement of Kinanthropometry. Subcutaneous fat mass was calculated using the Jackson and Pollock 7-site (chest, mid-axilla, suprailiac, abdomen, thigh, triceps and subscapula) skinfold test performed monthly between 1999 and 2006 but then twice per month from 2006 onwards. ${ }^{18}$ The mean score from each season was calculated. Fat-free mass was obtained by subtracting the derived fat mass from the body mass.

Maximal running speed was determined from a $40 \mathrm{~m}$ straight-line shuttle sprint test between 1996 and 2005 . This test was conducted under strict indoor testing conditions using timing light gates (Brower Timing Systems, Draper, Utah, USA) with light beam gates situated at $0 \mathrm{~m}, 10 \mathrm{~m}$ and $40 \mathrm{~m}$. Speed was calculated using the time taken to complete $30 \mathrm{~m}$ (from the $10 \mathrm{~m}$ gate to the $40 \mathrm{~m}$ gate) and converted into metres per second. These tests were typically conducted three or four times per season. Multiple variables affect the maximal speed in training scenarios, including (but not limited to) wind speed and direction and the player's training load immediately before testing. Each player's maximal speed at any point during each season was recorded as the score. Mean values were not used because of the effects of external factors described above and relatively infrequent testing.

From 2006 onwards, Global Positioning Satellite (GPS) (Catapult, Melbourne, Australia) systems became the standard for appraising player speeds within the elite rugby fraternity. Maximal speeds could thus be determined from any training session regardless of location, surface or weather conditions. GPS has been shown to reliably and accurately measure running speed in rugby players. $^{19}$

Momentum was calculated as the product of player body mass (in $\mathrm{kg}$ ) and maximum speed (in $\mathrm{m} / \mathrm{s}$ ) and expressed in kilogram metre per second $(\mathrm{kg} \cdot \mathrm{m} / \mathrm{s})$.

Kinetic energy was calculated from the equation $1 / 2 \mathrm{mv}^{2}$, where $\mathrm{m}$ is player body mass (in $\mathrm{kg}$ ) and $\mathrm{v}$ is the velocity (in $\mathrm{m} / \mathrm{s}$ ) and expressed in Joules $(\mathrm{J})$.

Distance covered during competitive matches was determined from GPS devices worn under or within players' shirts, starting in 2011. Each season the mean distance covered in matches was calculated for each player. To correct for players who were substituted (tactically or due to injury), the match-play distance was calibrated to a full $80 \mathrm{~min}$ play. For example, if a player covered $5000 \mathrm{~m}$ and was substituted after $60 \mathrm{~min}$, their ' $80 \mathrm{~min}$ distance' was calculated as:

$$
((1-60 / 80) \times 5000)+5000=6250 m
$$

When players were on the pitch for $<50 \mathrm{~min}$, this measure was prospectively not included; when players were sin-binned (off the pitch for $10 \mathrm{~min}$ as punishment for infringements) or temporarily removed from the field of play to undergo head injury assessment, this time was accounted for as described above.

\section{Statistical methodology}

To analyse the data, we divided the players into groups according to playing position, namely: Front Five (FF; props, hookers, second rows), Back Row (BR; flankers and number 8), Half-Backs (HB; scrum-half and flyhalf/stand-off/first five-eighth), Back Five (BF; centres, wings, full backs). Each player's first season of observation was then taken as their baseline. Data were analysed 
using STATA V.13 for Windows (Stata, College Station, Texas, USA). Continuous variables were summarised as medians (IQR). Categorical variables were summarised as percentages. Significant variation between groupings was evaluated for continuous variables using Kruskal-Wallis one-way analyses of variance and for categorical variables by $\chi^{2}$ tests. Players varied in the number of seasons for which data were recorded; therefore, changes in anthropometric and performance measures with seasons played were evaluated using mixed model regression analysis with individual ID number as grouping variable (STATA command: 'mixed'). Mixed model analysis was also used to evaluate interactions between the number of seasons played and position, club and international status in the changes in anthropometric and performance measures observed.

\section{RESULTS}

We analysed anthropometric and performance data of 291 professional rugby union players over a 20 -season period from 1999 to 2019. For the first data collection, the mean $(\mathrm{SD})$ age was $24.0( \pm 3.7)$ years. Of these, 227 (78\%) had between 2 and 11 seasons of observations recorded. There was no significant difference in initial age between the four groups of players by position: FF 24.1 ( \pm 3.7 years), BR $23.2( \pm 4.0)$ years, HB $24.5( \pm 3.4)$ years, BF $24.0( \pm 3.6)$ years; $\mathrm{p}=0.36$.

The distribution of players within each playing group was not significantly different between the three clubs $(p=0.79)$. Likewise, the proportions of elite professional or international players represented in the data did not differ between clubs $(p=0.69)$, nor was there a difference in elite professional or international status by position played ( $\mathrm{p}=0.32$ ).

There was a highly significant variation by position in every anthropometric and performance measure (table 1). Not unexpectedly, forwards were heavier than backs, with FF heaviest and HB lightest of the playing groups. Likewise, backs were faster than forwards at baseline. With each successive season played, players became bigger, leaner and faster; body mass, fat-free mass, maximum speed and momentum increased significantly, and per cent fat decreased (table 2). Body fat decreased from $15.4 \%( \pm 0.0)$ in 1999 to $12.3 \%( \pm 0.0)$ in 2019 . The mean maximal velocity of a rugby player in 1999 was 8.2 $( \pm 0.18) \mathrm{m} / \mathrm{s}$, which in 2019 had risen to $9.1( \pm 0.10) \mathrm{m} / \mathrm{s}$. Momentum, the product of mass and speed, increased by $>12 \mathrm{~kg} \cdot \mathrm{m} / \mathrm{s}$ each season. The momentum of players in 2019 was 14\% more than those playing in 1999 across all player cohorts; in the $\mathrm{FF}$, the increase in this period was $>25 \%$.

Finally, we grouped seasons in 4-year blocks (aligned with the Rugby World Cup cycle) and found similar results in anthropometric (figure 1) and performance parameters (figure 2A,B). Distance covered increased for all player groups except $\mathrm{BR}$, with the backs covering most distance.

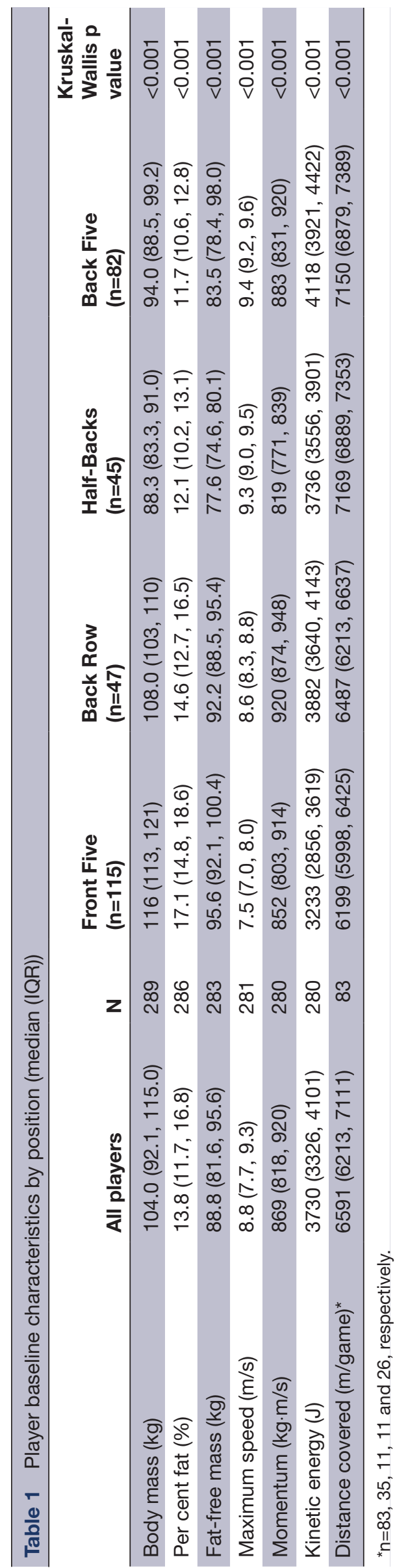


Table 2 Mixed-effects model-derived change in characteristic per season played (coefficient $(95 \% \mathrm{CI})$ )

\begin{tabular}{lll}
\hline & $\begin{array}{l}\text { Change per season } \\
\text { (904 observations for 291 } \\
\text { players) }\end{array}$ & $\begin{array}{l}\mathbf{P} \\
\text { value }\end{array}$ \\
\hline Body mass $(\mathrm{kg})$ & $+0.512(0.406$ to 0.618$)$ & $<0.001$ \\
\hline Per cent fat $(\%)$ & $-0.408(-0.475$ to -0.341$)$ & $<0.001$ \\
\hline Fat-free mass $(\mathrm{kg})$ & $+0.896(0.772$ to 1.020$)$ & $<0.001$ \\
\hline $\begin{array}{l}\text { Maximum speed } \\
\text { (m/s) }\end{array}$ & $+0.063(0.045$ to 0.082$)$ & $<0.001$ \\
\hline $\begin{array}{l}\text { Momentum }(\mathrm{kg} \cdot \mathrm{m} / \mathrm{s}) \\
\text { Kinetic energy }(\mathrm{J})\end{array}$ & $+12.1(9.6$ to 14.6$)$ & $<0.001$ \\
\hline $\begin{array}{l}\text { Distance covered } \\
\text { (m/game) }\end{array}$ & $+11.4(-6.4$ to 29.3$)$ & $<0.001$ \\
\hline
\end{tabular}

*344 observations for 142 players.

BR players had the greatest momentum at each time point (figure 2C). In particular, FF players had a large gain in momentum for the seasons 2015-2018 compared

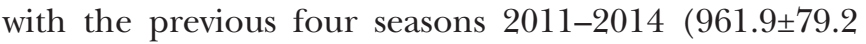
vs $888.1 \pm 70.8 \mathrm{~kg} \cdot \mathrm{m} / \mathrm{s})$. This appears to be mostly due to gain in speed in FF players (rather than increased body mass). When comparing the first four seasons combined (1999-2002) and the last four seasons (2015-2018) data, body mass of the BF increased by $4 \%$, HBs decreased by $0.5 \%$, BR increased by $2.6 \%$ and $\mathrm{FF}$ by $3.8 \%$. However, when investigating changes in speed over the same timelines, the maximum speed of BF increased by $2.2 \%$, that of $\mathrm{HB}$ and BR by $5.0 \%$ and the top speed of BR by $11.5 \%$. Momentum increased across all 20 seasons, whether baseline data or all readings from each player, were considered (online supplemental figure 1).

Players capped at full international level had less percentage body fat, were faster with greater momentum and kinetic energy and covered more distance than those who played at club level (table 3 ).
With each season played, in both international and club professional players, per cent fat decreased significantly, and body mass, muscle mass, speed, momentum and kinetic energy increased significantly (table 4 ). The rates of change per season appeared consistently less in international players than club professionals. Mixed-effects model analysis of these apparent interactions between international status and rate of change in anthropometric and performance indicators revealed that, in international players, per cent fat decreased per season by $0.161 \%$ less than in club professionals $(p=0.02)$. At borderline significance, in international players, muscle mass increased by $0.250 \mathrm{~kg}$ less than in club professionals $(\mathrm{p}=0.05)$.

These analyses were repeated with data stratified according to the position played, with 'forwards' distinguished as the FFs and BR and 'backs' as the $\mathrm{HB}$ and BF. These analyses showed that the lower rate of decline in per cent fat and the lower rate of increase in muscle mass in international players was restricted to the forwards. Per cent fat decreased per season in international forwards by $0.22 \%$ less than in club professionals $(\mathrm{p}=0.01)$ and muscle mass increased by $0.33 \mathrm{~kg}$ less $(\mathrm{p}=0.05)$ in international forwards.

Among the backs, the only difference between international and club professional players in the rate of change with season played in anthropometric and performance measures was a reduction in distance covered per season in international players compared with an increase in club professionals. In international backs, the distance covered was $75.4 \mathrm{~m}$ less per season than club professional backs ( $\mathrm{p}=0.039)$.

Grouped in 4-year blocks of seasons, international backs had a mean momentum of around $890 \mathrm{~kg} \cdot \mathrm{m} / \mathrm{s}$ with little variation. Club-level backs maintained a significantly lower momentum of around $830 \mathrm{~kg} \cdot \mathrm{m} / \mathrm{s}$ until the final quintile (2015-2018), when they matched the international players (online supplemental figure 2).
A

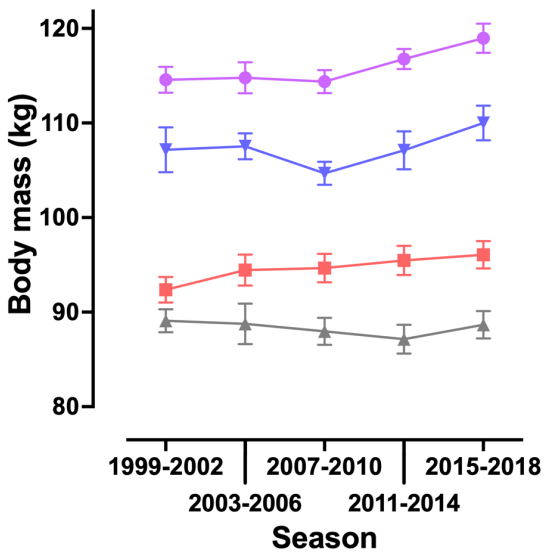

B

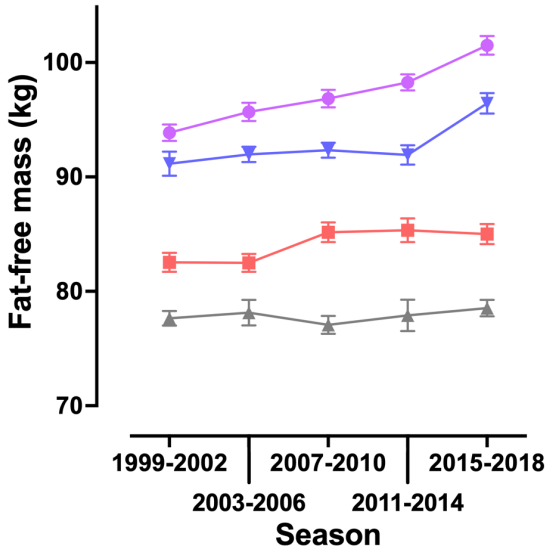

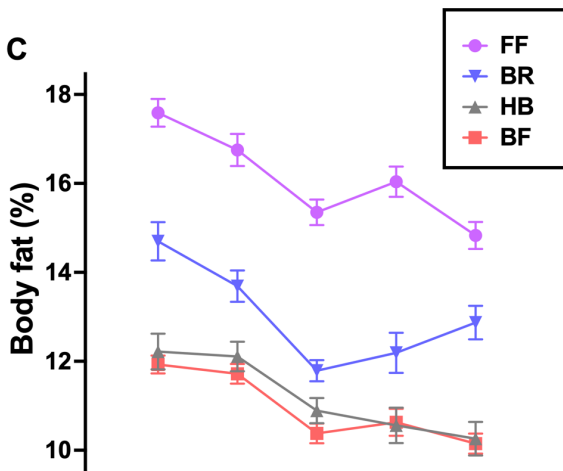

\begin{tabular}{c|c|c}
\hline 1999-2002 & $2007-2010$ & $2015-2018$ \\
\hline
\end{tabular} 2003-2006 2011-2014 Season

Figure 1 Anthropometric data of professional rugby players grouped into 4-year quintiles. Mean body mass (A) $n=289$. Fatfree mass (B) $n=283$. Body fat $(C) n=286$. BF, Back Five; BR, Back Row; HB, Half-Backs; FF, Front Five. 

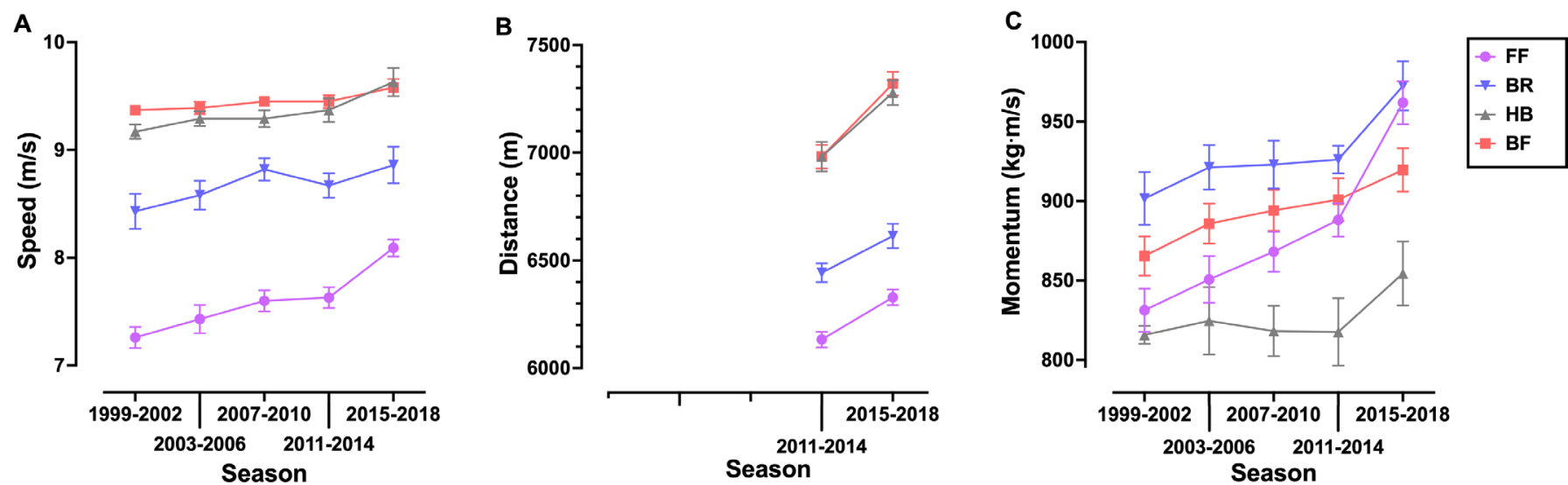

Figure 2 Performance and momentum data of professional rugby players grouped into 4-year quintiles. Maximum speed (A) $n=291$ players; distance covered (B) $n=83$ players and momentum (C) $n=280$ players. BF, Back Five; BR, Back Row; HB, Half-Backs; FF, Front Five.

\section{DISCUSSION}

We previously described significant increases in the body mass of northern hemisphere international rugby union players following the game turning professional. We stated that while players were able to increase their body mass, we hypothesised that they would be unable to increase their running speed significantly. ${ }^{4}$ In this paper, we describe changes in anthropometric and performance measurements in professional rugby union players for 20 seasons, commencing in 1996 when the game became fully professional.

\section{Anthropometric measurements}

Body mass increased significantly over time in our cohort of professional players, driven by clubs' developing professional infrastructure and supported by the laws of the game. Others have described similar increases in body mass in professional and elite youth rugby players over time. $^{2320}$ Interestingly, this gain in mass was most noticeable among forwards. In particular, the FF players, on average, gained $6.9( \pm 3.0) \mathrm{kg}$. There were smaller increases in BR players and little or no change in either group of backs. Fluctuation in fat mass also occurred over the course of 20 seasons; strikingly though, the trend is of significant reductions in per cent body fat which appears not to have fully plateaued. Thus, even players who did not gain total body mass will have lost fat and thus gained lean body mass. This is confirmed by large increases in fat-free mass (which can be roughly equated to muscle mass) in both forward groups.

\section{Performance measurements}

At all levels of rugby, acceleration and running speed remain sought-after qualities. Traditionally, the outside backs have traded on speed and have increased body mass to reinforce this advantage in recent years. ${ }^{23}$ Our data show that while the $\mathrm{BF}$ players remain the fastest on the pitch, the FF forwards have gained body mass and significantly increased their speed, thus disproving our initial hypothesis. This was based on our erroneous assumption that players peak speeds had already largely plateaued. Between 1999 and 2018, the time for the men's $60 \mathrm{~m}$ sprint record improved by $1.1 \%$, whereas elite rugby players' maximal speed increased by nearly $10 \%$ in the same timeframe.

Distance covered did not significantly increase overall; however, positional increases in the backs and FF players occurred. The distances recorded in this dataset are larger than those published from Super 14 rugby matches in the 2008 and 2009 seasons (between $4218 \mathrm{~m}$

\begin{tabular}{llll}
\hline Table 3 & Player baseline characteristics by international status (median (range)) & & \\
\hline & $\begin{array}{l}\text { International } \\
(\mathbf{n = 1 3 0 )}\end{array}$ & $\begin{array}{l}\text { Elite professional } \\
(\mathbf{n = 1 6 1 )}\end{array}$ & $\begin{array}{l}\text { Kruskal-Wallis } \\
\mathbf{p} \text { value }\end{array}$ \\
\hline Body mass $(\mathrm{kg})$ & $103.0(94.0,115.0)$ & $105.0(91.3,115.0)$ & 0.6 \\
\hline Per cent fat $(\%)$ & $13.1(11.2,15.8)$ & $14.2(12.2,17.0)$ & $<0.001$ \\
\hline Muscle mass $(\mathrm{kg})$ & $89.2(82.1,96.3)$ & $88.6(79.7,94.9)$ & 0.1 \\
\hline Maximum speed $(\mathrm{m} / \mathrm{s})$ & $9.0(7.6,9.4)$ & $8.6(7.7,9.2)$ & $<0.001$ \\
\hline Momentum force $(\mathrm{kg} \cdot \mathrm{m} / \mathrm{s})$ & $879(834,927)$ & $849(807,913)$ & $<0.001$ \\
\hline Kinetic energy $(\mathrm{J})$ & $3796(3397,4182)$ & $3704(3258,4023)$ & $<0.001$ \\
\hline Distance covered $(\mathrm{m} / \mathrm{game})^{*}$ & $6793(6304,7185)$ & $6448(6108,6943)$ & $<0.001$ \\
\hline
\end{tabular}

${ }^{*} \mathrm{n}=47$ and 36 , respectively. 
Table 4 Change per season in characteristics by international status (coefficient (SE) p for coefficient)

\begin{tabular}{lll}
\hline & $\begin{array}{l}\text { International } \\
\text { (490 observations for 130 players) }\end{array}$ & $\begin{array}{l}\text { Club professional } \\
\text { (n=414 observations for 161 } \\
\text { players) }\end{array}$ \\
\hline Body mass $(\mathrm{kg})$ & $+0.483(0.067)^{<0.001}$ & $+0.552(0.088)^{<0.001}$ \\
\hline Per cent fat $(\%)$ & $-0.316(0.036)^{<0.001}$ & $-0.539(0.062)^{<0.001}$ \\
Muscle mass $(\mathrm{kg})$ & $+0.763(0.070)^{<0.001}$ & $+1.09(0.114)^{<0.001}$ \\
Maximum speed $(\mathrm{m} / \mathrm{s})$ & $+0.053(0.011)^{<0.001}$ & $+0.077(0.015)^{<0.001}$ \\
Momentum force $(\mathrm{kg} \cdot \mathrm{m} / \mathrm{s})$ & $+10.8(1.49)^{<0.001}$ & $+14.0(2.16)^{<0.001}$ \\
\hline Kinetic energy $(\mathrm{J})$ & $+68.3(10.5)^{<0.001}$ & $+91.4(14.9)^{<0.001}$ \\
\hline Distance covered $(\mathrm{m} / \mathrm{game})$ & $-3.65(11.7)^{0.7}$ & $+27.3(16.4)^{0.09}$ \\
\hline
\end{tabular}

${ }^{*} n=180$ observations for 69 players and 164 observations for 73 players, respectively.

and $6389 \mathrm{~m}$ depending on position). ${ }^{21}$ Data from 763 players who played for or against New Zealand between 2004 and 2010 also demonstrated positional differences, with backs covering more distance with ball in play, and at higher speeds. ${ }^{22}$ Backs total distance $(5700-6300 \mathrm{~m})$ was greater than forwards $(5400-5700 \mathrm{~m})$ but it was noted that forwards sustained notably more collisions. ${ }^{22}$ Some of this variance may relate to the methodology used (time-motion analysis of video recordings). In 2009, GPS data were published on two professional players taking part in matches in the UK and reported similar distances covered for the forward and back who were studied compared with our data. ${ }^{23}$ In 2012, forwards in European Cup fixtures covered $4906 \mathrm{~m}$ and backs $5959 \mathrm{~m}$, and in Japanese professional rugby in 2013-2014, a mean distance of $6041 \mathrm{~m}$ was covered. ${ }^{24}{ }^{25}$ More recently, the distance covered in age-grade matches in the UK and university rugby in South Africa highlights the difference in fitness levels between youth/university-level sport and professional rugby. ${ }^{26}{ }^{27}$ Our data suggest increases in aerobic capacity, such that players can continue to run for longer or cover more distance earlier in the game.

\section{Momentum}

The combination of increased player mass and maximal velocity has seen the concept of momentum rise as a variable of importance in a sport that values contact. ${ }^{28} 29$ Momentum, a vector force, has seen steady growth for the 20 seasons studied, most markedly in the forwards. In the context of the large number of collisions that occur during a game $(0.7-0.9$ per min for forwards, $0.3-0.4$ per min for backs), greater momentum may make the chance of 'winning' contact situations and provide a significant advantage to the team. However, this effect may be negated if the opposing team has equivalent gains in momentum. ${ }^{30}$ Kinetic energy is less well reported and is not directional, as momentum is. Kinetic energy is more affected by changes in velocity than mass. Ranking player groups (by position), BR and BF players have greater momentum and kinetic energy than the front row and $\mathrm{HB}$ (kinetic energy: $\mathrm{BF}>\mathrm{BR}>\mathrm{HB}>\mathrm{FF}$ and momentum: $\mathrm{BR}>\mathrm{BF}>\mathrm{FF}>\mathrm{HB})$.
In rugby league, momentum is greater in first division (national) than second division (state) players. ${ }^{31}$ While this could be because first division players are coached to achieve greater momentum after selection for the different attribute(s), it has been suggested that momentum may be a valid talent identification metric capable of highlighting players able to succeed at the highest levels. Momentum increases with age in academy rugby union players (under 16, under 18 and under 21) to a peak of $810 \pm 93 \mathrm{~kg} \cdot \mathrm{m} / \mathrm{s}$ in the older group. ${ }^{10} 3233$ There is also an indication that momentum may have been used as a metric for talent identification; rugby league youth academy players who become professional players have (along with other physical attributes) greater momentum than those who do not. ${ }^{1032} 34$ Additionally, university students who went on to become professional rugby union players did not have significantly greater momentum (in both forwards and backs) than those who did not (personal correspondence, based on the study by Hamlin et al). ${ }^{35}$ While it is recognised that rugby union, rugby league and American football players have collectively gained body mass, it should also be understood that individuals frequently gain mass during their careers. ${ }^{20} 36$ Recognising that, in general, heavier players are slower than lighter players, optimising players' body mass and, where possible, speed according to the position they play in, their skills, and the tactical intent of the team presents a challenge to both players and coaches.

\section{International and club players}

Momentum and kinetic energy were initially greater in international players. Interestingly, the momentum of international backs did not change over the study period; where previously they held a statistical advantage over their less forceful club-level teammates, this difference no longer exists, suggesting a degree of catch-up by the club-level players. Likewise, the momentum of international-level and club-level forwards has been equally matched for $>10$ years. It is important to recognise that the observed changes between international and club players are small, nuanced and may not translate to real-world effects. Thus, momentum may differentiate 
academy from school adolescent rugby players, but in established professionals, it cannot discriminate between international and club players. ${ }^{8}$ This suggests that other factors beyond the force of impact determine selection at the international level; these may include sporting intelligence, strength, agility, individual skills (tackling, passing, kicking), teamwork and leadership. There is, for most, a threshold below which people are physically unsuited to professional rugby, however once at or above that level, being big and fast will only get you so far.

\section{Implications of findings}

The changing nature of anthropometry and performance metrics leads to significant concerns over player safety, law-making and adherence, consideration of training strategies. ${ }^{13-16}$

\section{Substitution laws}

Up to eight tactical substitutions are allowed in rugby union; this generates a performance environment whereby players can be substituted if their performance falls, allowing further fresh players to enter the field of play to compete against fatigued players. In a game where the number of collision events (tackles and rucks) per fixture has increased from 139 at the 1999 Rugby World Cup to 211 in 2019, and the number of ball carries gone up by $27 \%$ in the same timeframe, this is of particular relevance given the current concerns for player welfare. ${ }^{37}$ The risk of tackle injury is nearly doubled in professional players relative to players from lower tiers of the game. ${ }^{38}$ FF forwards are the most likely to be substituted (often after about an hour of a match) and are those who have the greatest momentum along with the BR. Notwithstanding the legal action being prosecuted by a group of former players diagnosed with dementia linked to repeated head injuries and early retirements due to injury, World Rugby has made rule changes (around tackle height) to reduce the number of concussive and subconcussive injuries sustained. Anthropometric changes as a possible cause or risk factor for injuries sustained in tackle situations were not discussed in a recent narrative review. Still, it was noted that these injuries, typically the most severe, occur relatively more frequently towards the end of the match attributed to fatigue affecting tackle technique. ${ }^{38}$ While it is feasible that better player conditioning for contact could mitigate some of the effects of increased momentum on injuries, the current substitution laws enable mismatches which may increase the risk of mistimed or misplaced collisions, especially later in the game. An open letter from the Progressive Rugby organisation has directly called substitutions to be used for injury only (https://progressiverugby.org/). This ensures that all players on the pitch measure their energy expenditure, expecting to complete $80 \mathrm{~min}$ and that all players are similarly fatigued. Studies are required to assess the potential impact on injuries, but this structure may favour lighter players.
The flow of the game

The adoption of video technology to assist refereeing decisions at the highest levels of the game has led to prolonged delays during the match where foul-play and the validity of scores are checked to ensure fairness. Some games now last $>2$ hours with slow movement from setpiece to set-piece. These well-intentioned interventions may have become unintentional enablers of the physical 'arms race' by allowing heavier players, who fatigue faster, greater opportunity to recover and continue playing at a higher intensity with less need to conserve energy. Likewise, there are frequent delays for discussion among players before scrums and line-out, with water carriers, medical staff and others coming onto the pitch. To support a faster game, referees might stop play only for gross law infringements, limiting interventions for minor offences and playing longer advantage periods, as well as penalising delays to a line-out or scrum.

\section{Laws of the game}

We have previously stated that failing to adhere to setpiece laws may have driven changes in players' physical characteristics. ${ }^{4}$ Allowing the scrum feed to be crooked has enabled larger hookers in the front row and the call for a straight put-in at the scrum, along with refereeing the ruck as set down in the laws of the game. Similarly, allowing players to lift one another in the line-out has coincided with a significant gain in the body mass of second-row forwards. If they were to have to jump for the ball themselves, this may mean that lighter players, able to project themselves higher, would be more successful, stalling increases in body mass.

\section{The 'physical arms race'}

The development of greater forces applied by players coincides with enormous concern about player welfare in the form of injuries, recognised at the time and identified at later time points. As far as we are aware, it is not feasible to limit a player's speed or body mass. However, one route to lower the peak momentum regularly achieved would be to enforce a team 'weight limit' so that the combined body mass of the 15 players on the pitch did not exceed a predetermined total. This would allow teams to field some heavy players but may create an environment where lighter players with different physical attributes and skillsets are prioritised.

\section{Limitations}

A limitation of these data relates to it being comprising three teams, and thus there are two time-points at which whole squads' change (in 2003 and 2014) may have affected some of the results. Mitigating this, player turnover within a team was typically $10-15$ players per season in squads of 45-50 personnel. We extrapolated distance covered in players who left the field after $>50 \mathrm{~min}$ of playing (either through injury or tactical substitution), which may over-represent the results of the player groups frequently replaced after about $60 \mathrm{~min}$ (eg, often the 
entire front row). It should also be mentioned that information that would enable us to relate the significant changes we observed to changes in actual risk of physical injury was not available. Nevertheless, circumstantially, the increases in mass and momentum with the time that we observed did coincide with increased rates of injury reported over the same period, encouraging more focused attention on the quantitative relationship between performance measures and injury risk.

GPS was not established as the gold-standard measurement platform for all teams until around 2010. Despite using the same sprint dash times over timing gates as their maximal speed measurement tools, some used $30 \mathrm{~m}$. In contrast, others used $40 \mathrm{~m}$ as a distance. A limitation is the reliability of the conversion of $\mathrm{m} / \mathrm{s}$ from the maximal speed obtained from a 'flying' $30 \mathrm{~m}$ to its measurement using GPS systems.

\section{Summary}

Our new dataset, gathered over 20 seasons of top-flight rugby, has shown that professional players are now leaner, heavier, faster and cover more distance than ever before. When professional rugby players collide, the forces involved have risen. The implications of this are yet to be fully understood. Still, a growing evidence base for concerns over head injuries means serious consideration of longitudinal datasets such as this, and how to address the consequences of players' changes over time is now urgently required.

\section{Twitter Nick S Oliver @mortdecai}

Acknowledgements The authors would like to thank Professor Mike Hamlin for generous assistance and sharing of anonymised data.

Contributors TGB collected the data; IG did the statistics; NEH, TGB, NSO and SC wrote the manuscript; all authors have reviewed and approved the final draft of the paper. NEH is the guarantor and accepts full responsibility for the work, had access to the dat and controlled the decision to publish.

Funding The authors have not declared a specific grant for this research from any funding agency in the public, commercial or not-for-profit sectors.

Competing interests None declared.

Patient and public involvement Patients and/or the public were not involved in the design, or conduct, or reporting, or dissemination plans of this research.

\section{Patient consent for publication Not applicable.}

Ethics approval The data used for this study were collected as part of the usual work of the Strength and Conditioning team at three professional rugby clubs and was not collected for academic use. The authors have written informed permission to use anonymised data obtained from the Data Guardian at each professional rugby club.

Provenance and peer review Not commissioned; externally peer reviewed.

Data availability statement Data are available on reasonable request. Available on reasonable request from corresponding author, providing the data owners give permission for the data to be released.

Open access This is an open access article distributed in accordance with the Creative Commons Attribution Non Commercial (CC BY-NC 4.0) license, which permits others to distribute, remix, adapt, build upon this work non-commercially, and license their derivative works on different terms, provided the original work is properly cited, appropriate credit is given, any changes made indicated, and the use is non-commercial. See: http://creativecommons.org/licenses/by-nc/4.0/.

ORCID iD

Neil E Hill http://orcid.org/0000-0002-4359-2646

\section{REFERENCES}

1 Olds T. The evolution of physique in male rugby union players in the twentieth century. J Sports Sci 2001;19:253-62.

2 Hill NE, Rilstone S, Stacey MJ, et al. Changes in northern hemisphere male international rugby union players' body mass and height between 1955 and 2015. BMJ Open Sport Exerc Med 2018;4:e000459.

3 Tucker R, Lancaster S, Davies P, et al. Trends in player body mass at men's and women's rugby world CUPS: a plateau in body mass and differences in emerging rugby nations. BMJ Open Sport Exerc Med 2021;7:e000885.

4 Fuller CW, Taylor AE, Brooks JHM, et al. Changes in the stature, body mass and age of English professional rugby players: a 10-year review. J Sports Sci 2013;31:795-802.

5 Stephens D, Fourie J. Morphological evolution of Springbok rugby players: implications for racial transformation in South African rugby. S Afr J Res Sport Phys Educ Recreat 2017;39:145-61.

6 Quarrie KL, Hopkins WG. Changes in player characteristics and match activities in Bledisloe cup rugby Union from 1972 to 2004. J Sports Sci 2007;25:895-903.

7 Sedeaud A, Marc A, Schipman J, et al. How they won rugby world cup through height, mass and collective experience. Br J Sports Med 2012;46:580-4.

8 Jones B, Weaving D, Tee J, et al. Bigger, stronger, faster, fitter: the differences in physical qualities of school and Academy rugby union players. J Sports Sci 2018;36:2399-404.

9 NZRPA retired player survey. Available: https://www.nzrpa.co.nz/pdf/ NZRPA-Retired-Player-Survey-FINAL.pdf [Accessed 12 Dec 21].

10 Harsh facts of rugby playing career revealed. Available: https://www. irishexaminer.com/sport/rugby/arid-20247304.html [Accessed 02 Sep 2021].

11 Laws of the game. Available: https://www.world.rugby/the-game/ laws/home

12 Tee JC, Lambert MI, Coopoo Y. Impact of fatigue on positional movements during professional rugby Union match play. Int J Sports Physiol Perform 2017;12:554-61.

13 Sir lan McGeechan tells world rugby: this sport is too dangerous act now before a player dies. Available: https://www.thetimes.co.uk/ article/reduce-number-of-subs-before-player-dies-lions-legends-tellworld-rugby-qjjmpw5z6 [Accessed 02 Sep 2021].

14 Rugby world cup winner Steve Thompson reveals he has dementia and joins landmark legal case. Available: https://www. theguardian.com/sport/2020/dec/08/steve-thompson-former-rugbyunion-players-dementia-landmark-legal-case\#: :text=Steve\% 20Thompson\%2C\%20who\%20won\%20the,legal\%20action\% 20for\%20the\%20sport [Accessed 02 Sep 21]

15 Pietro DV, O'Halloran P, Watson CN. Unique diagnostic signatures of concussion in the saliva of male athletes: the study of concussion in rugby Union through microRNAs (SCRUM). Br J Sports Med 2021;23:bjsports-2020-103274.

16 Owens TS, Calverley TA, Stacey BS, et al. Contact events in rugby Union and the link to reduced cognition: evidence for impaired redox-regulation of cerebrovascular function. Exp Physiol 2021;106:1971-80.

17 Lohman TG, Roche AF, Mortorell R. Anthropometric standardization reference manual. Champaign, IL: Human Kinetics, 1988.

18 Jackson AS, Pollock ML. Generalized equations for predicting body density of men. Br J Nutr 1978;40:497-504.

19 Lacome M, Peeters A, Mathieu B, et al. Can we use GPs for assessing sprinting performance in rugby sevens? A concurrent validity and between-device reliability study. Biol Sport 2019;36:25-9.

20 Lombard WP, Durandt JJ, Masimla H, et al. Changes in body size and physical characteristics of South African under-20 rugby union players over a 13-year period. J Strength Cond Res 2015;29:980-8.

21 Austin D, Gabbett T, Jenkins D. The physical demands of super 14 rugby Union. J Sci Med Sport 2011;14:259-63.

22 Quarrie KL, Hopkins WG, Anthony MJ, et al. Positional demands of international rugby Union: evaluation of player actions and movements. J Sci Med Sport 2013;16:353-9.

23 Cunniffe B, Proctor W, Baker JS, et al. An evaluation of the physiological demands of elite rugby Union using global positioning system tracking software. J Strength Cond Res 2009;23:1195-203.

24 Jones MR, West DJ, Harrington BJ, et al. Match play performance characteristics that predict post-match creatine kinase responses in professional rugby union players. BMC Sports Sci Med Rehabil 2014;6:38.

25 Yamamoto H, Takemura M, Kaya M. Physical demands of elite rugby Union match-play using global positioning system. Football Sci 2017:14:15-23. 
26 Till K, Weakley J, Read DB, et al. Applied sport science for male Age-Grade rugby union in England. Sports Med Open 2020;6:14

27 Donkin C, Venter R, Coetzee D, et al. Positional In-Match running demands of university rugby players in South Africa. Front Psychol 2020;11:1591.

28 Barr MJ, Sheppard JM, Gabbett TJ, et al. Long-Term training-induced changes in sprinting speed and sprint momentum in elite rugby union players. J Strength Cond Res 2014;28:2724-31.

29 Quarrie KL, Handcock P, Waller AE, et al. The New Zealand rugby injury and performance project. III. anthropometric and physical performance characteristics of players. Br J Sports Med 1995;29:263-70.

30 Reardon C, Tobin DP, Tierney P, et al. Collision count in rugby Union: a comparison of micro-technology and video analysis methods. $J$ Sports Sci 2017;35:2028-34.

31 Baker DG, Newton RU. Comparison of lower body strength, power, acceleration, speed, agility, and sprint momentum to describe and compare playing RANK among professional rugby League players. $J$ Strength Cond Res 2008;22:153-8.

32 Till K, Jones B, Geeson-Brown T. Do physical qualities influence the attainment of professional status within elite 16-19 year old rugby League players? J Sci Med Sport 2016;19:585-9.
33 Darrall-Jones JD, Jones B, Till K. Anthropometric, sprint, and highintensity running profiles of English Academy rugby union players by position. J Strength Cond Res 2016;30:1348-58.

34 Darrall-Jones JD, Jones B, Till K. Anthropometric and physical profiles of English Academy rugby union players. J Strength Cond Res 2015;29:2086-96.

35 Hamlin MJ, Deuchrass RW, Elliot CE, et al. Short and longterm differences in anthropometric characteristics and physical performance between male rugby players that became professional or remained amateur. J Exerc Sci Fit 2021;19:143-9.

36 Hoffman JR, Ratamess NA, Kang J. Performance changes during a College playing career in NCAA division III football athletes. $J$ Strength Cond Res 2011;25:2351-7.

37 Revolutionising rugby - a statistical analysis on how the game has evolved. Available: https://www.statsperform.com/resource/ revolutionising-rugby-a-statistical-analysis-on-how-the-game-hasevolved/ [Accessed 08 Sep 21]

38 Burger N, Lambert M, Hendricks S. Lay of the land: narrative synthesis of tackle research in rugby Union and rugby sevens. BMJ Open Sport Exerc Med 2020;6:e000645. 